\title{
Localized Pd Overgrowth on Cubic Pt Nanocrystals for Enhanced Electrocatalytic Oxidation of Formic Acid
}

\author{
Hyunjoo Lee ${ }^{\ddagger}$, Susan E. Habas ${ }^{\ddagger}$, Gabor A. Somorjai ${ }^{\ddagger}$, and Peidong Yang ${ }^{\ddagger}$ \\ Department of Chemical Engineering, Yonsei University, Seoul, South Korea, Department of Chemistry, University of \\ California, Berkeley, California 94720, USA, and Materials Sciences Division, Lawrence Berkeley National \\ Laboratory, Berkeley, California 94720, USA \\ Email:p_yang@uclink.berkeley.edu \\ RECEIVED DATE ;
}

Single crystalline surface such as (100), (111), (110) has been studied as an idealized platform for electrocatalytic reactions since the atomic arrangement affects a catalytic property. The secondary metal deposition on these surfaces also alters the catalytic property often showing improvement such as poisoning decrease. On the other hand, electrocatalysts used for practical purpose usually have a size on the order of nanometers. Therefore, linking the knowledge from single crystalline studies to nanoparticle catalysts is of enormous importance. Recently, the Pt nanoparticles which surface structure was preferentially oriented was synthesized and used as electrocatalysts ${ }^{12}$. Here, we demonstrate a rational design of a binary metallic nanocatalyst based on the single crystalline study.

Clavilier et al. studied the electro-oxidation of formic acid for Pd adsorbed on $\operatorname{Pt}(100)$ single crystal surfaces. ${ }^{5}$ They observed that the presence of adsorbed palladium on $\operatorname{Pt}(100)$ decreases selfpoisoning and lowers the oxidation potential considerably. The multi-metallic nanoparticle catalysts, however, were usually prepared by co-precipitation ${ }^{6}$ or electrodeposition ${ }^{7}$, and control over surface structure was not achieved. We present the synthesis and application of binary $\mathrm{Pt} / \mathrm{Pd}$ nanoparticles in which $\mathrm{Pd}$ decorates the well-defined surface of $\mathrm{Pt}$ nanoparticles. $\mathrm{Pt}$ nanocubes fully bound by (100) surfaces acted as seeds for overgrowth of Pd. Overgrowth was observed at multiple points on each seed, predominantly at the corners. Electro-oxidation of formic acid performed on these binary $\mathrm{Pt} / \mathrm{Pd}$ catalysts showed the same effects of less poisoning and lower oxidation potential expected from the single crystal study.

Preparation of metal nanoparticles with shape control has often been achieved by controlling growth rates on different facets through interactions with surface-stabilizing agents. ${ }^{8}$ However, since the catalytic activity is hindered by these surface-stabilizing agents, ${ }^{9}$ preserving the catalytic activity of the metal surface is crucial. In this study, we used tetradecyltrimethylammonium bromide (TTAB) as a surface-stabilizing agent since it has a weak interaction with metal surfaces ${ }^{9 \mathrm{a}}$. The cubic $\mathrm{Pt}$ nanoparticles used as seeds were prepared by reducing $\mathrm{K}_{2} \mathrm{PtCl}_{4}$ dissolved in aqueous TTAB solution with $\mathrm{NaBH}_{4}$ as previously reported. ${ }^{9 a}$ A TEM image of the cubic Pt seed particles is shown in Figure S1(a). Pd was nucleated on the surface of cubic Pt seeds upon reduction of $\mathrm{K}_{2} \mathrm{PdCl}_{4}$ by ascorbic acid in the presence of TTAB (See Supporting Information for more details). Figure 1(a) shows a low magnification TEM image of the binary $\mathrm{Pt} / \mathrm{Pd}$ nanoparticles. Single, double and multiple nucleation of $\mathrm{Pd}$ on $\mathrm{Pt}$ nanoparticles was observed with nucleation occurring primarily on the corners. High resolution TEM images in Figures 1(b) show the interface of
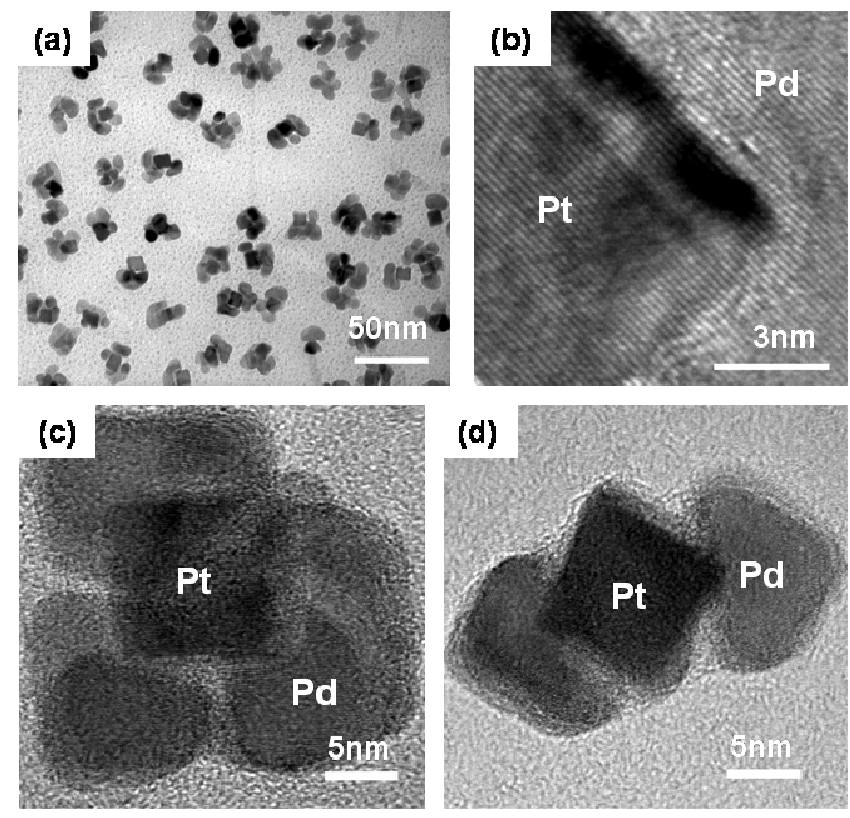

Figure 1. TEM images of (a) binary Pt/Pd nanoparticles, HR-TEM images of (b) $\mathrm{Pt} / \mathrm{Pd}$ interface with an atomic resolution, (c) high $\mathrm{Pd}$ coverage and (d) low Pd coverage of binary Pt/Pd nanoparticles.

the two metals more clearly. Pd grew on Pt surface epitaxially. Figure 1(c) and (d) show a high and low coverage of Pd on Pt surface. The formation of multiple nucleation sites of $\mathrm{Pd}$ on the $\mathrm{Pt}$ seeds rather than conformal overgrowth depends on the rate of reduction which was controlled through $\mathrm{pH}$. The addition of asmade Pt seeds (pH 9) also introduces the strongly basic metaborate ion $\left(\mathrm{BO}_{2}^{-}\right)$formed during the reaction of $\mathrm{NaBH}_{4}$ with water. The higher $\mathrm{pH}$ increases the rate of $\mathrm{Pd}$ reduction, probably due to better stabilization of the oxidized form of the ascorbic acid. The increased rate of reduction may encourage the formation of multiple nucleation sites rather than the conformal overgrowth of a thin Pd shell which was observed when the Pt seeds were acidified to a neutral $\mathrm{pH}^{10}$. The addition of base to bring the $\mathrm{pH}$ of the seed solution back to $\sim 9$ once again allows for the formation of multiple nucleation sites. Fully grown cubic Pd nanoparticles with a cubic Pt seed inside, shown in Figure S1(b), were prepared by decreasing the concentration of $\mathrm{Pt}$ seeds along with the $\mathrm{pH}$. This type of epitaxial overgrowth was demonstrated previously. ${ }^{12}$ While both the $\mathrm{Pt}$ and $\mathrm{Pd}$ surfaces are accessible on the binary $\mathrm{Pt} / \mathrm{Pd}$ nanoparticles, only the $\mathrm{Pd}$ surface is available on the coreshell $\mathrm{Pt} / \mathrm{Pd}$ nanocubes. Pd nanoparticles without $\mathrm{Pt}$ seeds were also prepared as shown in Figure S1(c) for comparison. 

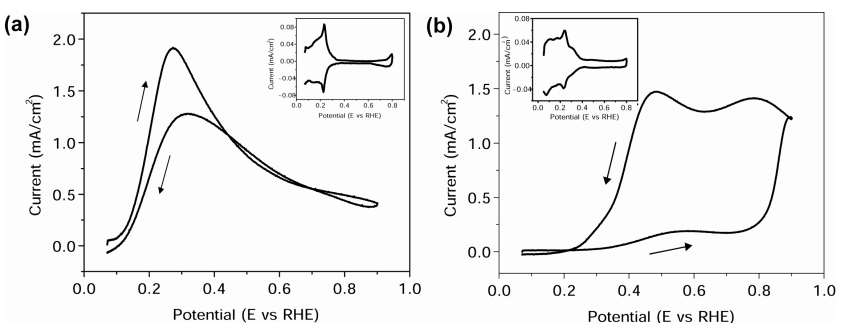

Figure 1. Cyclic voltammetric curves for (a) binary $\mathrm{Pt} / \mathrm{Pd}$ nanoparticles (b) Pt nanocubes in $0.25 \mathrm{M} \mathrm{HCOOH}+0.5 \mathrm{M} \mathrm{H}_{2} \mathrm{SO}_{4}$ solution at a scan rate of $50 \mathrm{mV} / \mathrm{s}$. The insets show blank voltammograms of the same electrodes in $0.5 \mathrm{M} \mathrm{H}_{2} \mathrm{SO}_{4}$ at $50 \mathrm{mV} / \mathrm{s}$.

Each type of nanoparticle, described above, was tested for formic acid oxidation. A washed and concentrated nanoparticle solution was deposited on a $\mathrm{Au}$ electrode and dried at room temperature. The presence of the stabilizing agents on the nanoparticle surface required measurement of the actual surface area that was accessible for reaction. The surface areas were estimated from $\mathrm{H}$ adsorption/desorption cyclic voltammograms (CV) taken in sulfuric acid solution, and the results for formic acid oxidation were normalized by the estimated surface areas. Clavilier et al. reported that no oxidation was observed in the positive sweep for a $\mathrm{Pt}(100)$ single crystal surface and a lower oxidation peak potential was observed when Pd was adsorbed on $\mathrm{Pt}(100)$ (0.23V for Pd-adsorbed on $\mathrm{Pt}(100)$ and $0.42 \mathrm{~V}$ for $\mathrm{Pt}(100))^{5}$. Under the same electrocatalytic conditions of $0.25 \mathrm{M}$ $\mathrm{HCOOH}+0.5 \mathrm{M} \mathrm{H}_{2} \mathrm{SO}_{4}$ at the scan rate of $50 \mathrm{mV} / \mathrm{s}$, the $\mathrm{CVs}$ of the nanoparticles were collected. Figure 2 shows the CVs for (a) binary $\mathrm{Pt} / \mathrm{Pd}$ nanoparticles and (b) $\mathrm{Pt}$ nanocubes. The insets provide blank $\mathrm{CV}$ s for the same sample in $0.5 \mathrm{M} \mathrm{H}_{2} \mathrm{SO}_{4}$ solution without the formic acid. CVs for core-shell Pd nanocubes and Pd nanoparticles synthesized without $\mathrm{Pt}$ seed were also shown in Figure S2(a) and S2(b), respectively. The $\mathrm{H}$ adsorption/desorption curves for Pt cubes and Pd cubes corresponds well with the CVs for clean (100) surfaces. The binary $\mathrm{Pt} / \mathrm{Pd}$ nanoparticles show an intermediate blank $\mathrm{CV}$ of $\mathrm{Pt}$ cubes and $\mathrm{Pd}$ cubes implying that both the Pt and Pd surface are accessible for the reaction.

In the case of the Pt cubes, the reaction is so strongly hindered by the spontaneous formation of poisoning intermediates that only minimal oxidation is observed in the positive $\operatorname{scan}^{5}$. Oxidation on Pt cubes only occurs in the reverse scan after the poison formed in the low range was oxidized and eliminated from the surface above $0.8 \mathrm{~V}$. On the other hand, no inhibition is observed in the positive scan for the binary $\mathrm{Pt} / \mathrm{Pd}$ nanoparticles. Also, oxidation occurs at a much lower potential range (nearly $0.2 \mathrm{~V}$ less) than that observed for Pt cubes $(0.27 \mathrm{~V}$ for binary $\mathrm{Pt} / \mathrm{Pd}$ nanoparticles and $0.48 \mathrm{~V}$ for Pt cubes). The presence of $\mathrm{Pd}$ on the surface of the $\mathrm{Pt}$ cubes prevents the poisoning in the positive scan and induces a considerable decrease in the activation energy for formic acid oxidation compared with Pt cubes. Oxidation of formic acid on $\mathrm{Pd}$ cubes and Pd nanoparticles synthesized without Pt seeds was also performed as a comparison. In both cases, no inhibition was observed in the positive scan while the peak oxidation potentials were as high as or even higher than that for Pt cubes $(0.45 \mathrm{~V}$ for the Pd cubes containing a Pt seed, and $0.52 \mathrm{~V}$ for pure $\mathrm{Pd}$ particles).

Pt is known to exhibit a dual path mechanism for the oxidation of formic acid. Direct dehydrogenation produces $\mathrm{CO}_{2}$ and $\mathrm{H}_{2}$, while dehydration produces $\mathrm{CO}$ and $\mathrm{H}_{2} \mathrm{O}$. The evolved $\mathrm{CO}$ acts as a self-poisoning intermediate. We performed the $\mathrm{CO}$ stripping and the $\mathrm{CV}$ curves demonstrated that the $\mathrm{CO}$ stripping peak is shifted towards a higher potential for the binary $\mathrm{Pt} / \mathrm{Pd}$ nanoparticles compared to the $\mathrm{Pt}$ cubes, while the $\mathrm{Pd}$ cubes and $\mathrm{Pd}$ nanoparticles synthesized without Pt seeds showed even higher $\mathrm{CO}$ stripping potentials (See Figure S3). Although a higher CO stripping potential indicates a lower $\mathrm{CO}$ tolerance, binary $\mathrm{Pt} / \mathrm{Pd}$ nanoparticles show little deactivation in the positive scan. Therefore, only direct dehydrogenation path producing $\mathrm{CO}_{2}$ and $\mathrm{H}_{2}$ seems to occur when $\mathrm{Pd}$ is adsorbed on Pt surface, which is also observed by other research groups ${ }^{11}$. Also, it was shown that formic acid oxidation on $\mathrm{Pt}$ follows dehydration pathway at low potential producing $\mathrm{CO}^{3 \mathrm{~b}}$. The minimized $\mathrm{CO}$ formation at low potential might enable to lower the peak potential for binary $\mathrm{Pt} / \mathrm{Pd}$ nanoparticles.

Binary $\mathrm{Pt} / \mathrm{Pd}$ nanoparticles were synthesized by localized overgrowth of $\mathrm{Pd}$ on cubic $\mathrm{Pt}$ seeds for investigation of electrocatalytic formic acid oxidation. The binary particles exhibit much less self-poisoning relative to Pt nanocubes and the lower activation energy, and these results are consistent with the single crystal study.

Acknowledgment. This work was supported by the Director, Office of Science, Office of Basic Energy Sciences, Materials Sciences and Engineering Division, of the U.S. Department of Energy under Contract No. DE-AC02-05CH1123. We thank the National Center for Electron Microscopy for the use of their facilities.

Supporting Information Available: Details for synthesis, characterization, and electrocatalytic measurements. This material is available free of charge via Internet at http://pubs.acs.org

1. Davis, S. M.; Zaera, F.; Somorjai, G. A. J. Catal. 1984, 85.

2. Bratlie, K. M.; Lee, H.; Komvopoulos, K.; Yang, P.; Somorjai, G. A. Nano Letters 2007, 7, 3097.

3. (a) Zhou, W. P.; Lewera, A.; Larsen, R.; Masel, R. I.; Bagus, P. S.; Wieckowski, A. J. Phys. Chem. B 2006, 110, 13393-13398. (b) Arenz, M.; Stamenkovic, V.; Schmidt, T. J.; Wandelt, K.; Ross, P. N.; Markovic, N. M. Phys. Chem. Chem. Phys. 2003, 5, 4242-4251.

4. (a) Baldauf, M.; Kolb, D. M. J. Phys. Chem. 1996, 100. (b) Hoshi, N.; Kida, K.; Nakamura, M.; Nakada, M.; Osada, K. J. Phys. Chem. B 2006, 110, 12480-12484. (c) Vidal-Iglesias, F. J.; Solla-Gullon, J.; Herrero, E.; Aldaz, A.; Feliu, J. M. Journal of Applied Electrochemistry 2006, 36, 1207-1214.

5. Llorca, M. J.; Feliu, J. M.; Aldaz, A.; Clavilier, J. Journal of Electroanalytical Chemistry 1994, 376, 151-160.

6. (a) Chen, W.; Kim, J.; Sun, S.; Chen, S. Phys. Chem. Chem. Phys. 2006, 8 , 2779-2786. (b) Ye, H.; Crooks, R. M. J. Am. Chem. Soc. 2007, 129, 36273633 .

7. Jayashree, R. S.; Spendelow, J. S.; Yeom, J.; Rastogi, C.; Shannon, M. A.; Kenis, P. J. A. Electrochimica Acta 2005, 50, 4674-4682.

8. (a) Jingyi Chen, T. H. Y. X. Angewandte Chemie International Edition 2005, 44, 2589-2592. (b) Teng, X.; Yang, H. Nano Lett. 2005, 5, 885-891.

9. (a) Lee, H.; Habas, S. E.; Kweskin, S.; Butcher, D.; Somorjai, G. A.; Yang, P. Angewante Chemi International Edition 2006, 45, 7824-7828. (b) Song, H.; Rioux, R. M.; Hoefelmeyer, J. D.; Komor, R.; Niesz, K.; Grass, M.; Yang, P.; Somorjai, G. A. J. Am. Chem. Soc. 2006, 128, 3027-3037.

10. Habas, S. E.; Lee, H.; Radmilovic, V.; Somorjai, G. A.; Yang, P. Nature Materials 2007, 6, 692-697.

11. Babu, P. K.; Kim, H. S.; Chung, J. H.; Oldfield, E.; Wieckowski, A. J. Phys. Chem. B 2004, 108, 20228-20232.

12. (a) Solla-Gullon, J.; Vidal-Iglesias, F. J.; Rodfriguez, P.; Herrero, E.; Feliu, J. M.; Clavilier, J.; Aldaz, A. J. Phys. Chem. B. 2004, 108, 13573-13575. (b) Tian, N.; Zhou, Z. Y.; Sun, S. G.; Ding, Y.; Wang, Z. L. Science 2007, 316, 732-735. 